\title{
The Effect of Tubificid Bioturbation on Vertical Water Exchange across the Sediment-Water Interface
}

\author{
Ruichen Mao ${ }^{1} \mathbb{D}$, Jintao $\mathrm{Wu}^{1}{ }^{1}$, Xin $\mathrm{Qin}^{1}{ }^{1}$, Chi Ma ${ }^{1}$, Jinxi Song ${ }^{1,2,3, *} \mathbb{C}$, Dandong Cheng ${ }^{1,2}$, \\ Haotian Sun ${ }^{1}$ and Mingyue $\mathrm{Li}^{1}$ \\ 1 College of Urban and Environmental Sciences, Northwest University, Xi'an 710127, China; \\ ruichenmao@stumail.nwu.edu.cn (R.M.); wujintao@stumail.nwu.edu.cn (J.W.); \\ qinxin123@stumail.nwu.edu.cn (X.Q.); chima@stumail.nwu.edu.cn (C.M.); \\ chengdandong@hotmail.com (D.C.); sunhaotian@nwu.edu.cn (H.S.); mingyueli@stumail.nwu.edu.cn (M.L.) \\ 2 State Key Laboratory of Soil Erosion and Dryland Farming on the Loess Plateau, \\ Institute of Soil and Water Conservation, CAS \& MWR, Yangling 712100, China \\ 3 Institute of Qinling Mountains, Northwest University, Xi'an 710127, China \\ * Correspondence: jinxisong@nwu.edu.cn; Tel.: +86-1500-929-4609
}

Received: 28 September 2020; Accepted: 8 December 2020; Published: 10 December 2020

\begin{abstract}
The bioturbation activity of macroinvertebrates can affect the level of water exchange across the sediment-water interface. The impact of tubificid worm with different densities on the vertical water exchange at the sediment-water interface was investigated based on laboratory flume experiments. Vertical water fluxes, as well as physiochemical parameters, were measured at seven-day intervals, and the maximum penetration depths were obtained by dye injection before and after the tubificid bioturbation experiment, respectively. The bioturbation effects can be summarized in two aspects: (1) when the density was less than (or equal to) 20 individual $/ 10 \mathrm{~cm}^{2}$, the volume of vertical water exchange positively correlated with the tubificid bioturbation. Once the density exceeded (or equaled) 25 individual $/ 10 \mathrm{~cm}^{2}$, the vertical water flux decreased with increasing tubificid bioturbation. After 14 to 21 days, a negative correlation was identified between the bioturbation and the vertical water flux under all biological densities. (2) The maximum depth that the surface water can penetrate the sediment increased with increasing tubificid density. These results revealed that the vertical water was closely related to the biological density. The study has certain reference significance to understanding the spatiotemporal heterogeneity of hyporheic water exchange on a local scale.
\end{abstract}

Keywords: tubificid bioturbation; vertical water exchange; sediment-water interface; tubificid density; experiment duration

\section{Introduction}

Among the factors that affect the size and activity of hyporheic zone, hyporheic water exchange is of particular importance, controlling the transfer of heat, the fate of contaminants, the nutrient cycling and the distribution of organic matter between stream and groundwater [1,2]. As an active moving component in the hyporheic sediment, pore water dynamically exchanges with the surface water [3]. Frequent water exchange between the stream and hyporheic sediment can further influence the metabolism and biogeochemical processes near the sediment-water interface (SWI) [4]. Gualtieri [5] demonstrated that flow hydrodynamics in the near-bed region could influence the mass-transfer processes across the SWI. The hydrological exchange allows the upwelling pore water to bring some primary producers (i.e., benthic plants and autotrophic bacteria) into the river, which produce organic matter, while the downwelling of surface water enters the sediment, transferring nutrients and 
dissolved oxygen to the hyporheic organisms [6]. Therefore, the intensity and size of water exchange occurring at the SWI are closely related to the ecological health of the river.

Previous studies have focused on the hydrological and biological factors affecting hyporheic water exchange, such as instream wood, bed form and microbial activity [7-12]. With hyporheic macroinvertebrates attracting more attention as ecosystem engineers, efforts have been undertaken to investigate the bioturbation-induced hyporheic processes [13-15]. Invertebrates, usually living in streambed sediment of rivers, lakes and oceans, are sensitive to human activities and natural factors, therefore, exhibiting variation in distribution, density, abundance, and biomass in the aquatic environment [16]. Bioturbation processes induced by hyporheic macroinvertebrate widely exist at the SWI, typically including burrowing, feeding, irrigating and defecating $[17,18]$. These activities can alter sediment structures by heightening the physical properties of the sediment (i.e., bulk density, permeability, hydraulic conductivity, porosity, and matrix stability) as well as flow conditions, which potentially impact the movement of substances and energy among stream water, sediment pore water and groundwater [19,20]. Mermillod-Blondin [21] proved that the movement of water from the water column to the sediment can be altered by bioturbation of benthic infaunal species. Such effects contribute to water exchange across the streambed. The impact of macroinvertebrates on hyporheic water flux has been further quantified in several studies $[15,22,23]$. Water flux obtained by the conservative-solute transport model before and after the introduction of invertebrate showed that the presence of tubificids significantly increased the proportion of mobile region, indicating modified water flux [24]. Research has also shown that the macroinvertebrate community may be related to the magnitude and patterns of water exchange [25]. The presence of tubificid worms can effectively enhance the water flux while the chironomid larvae failed to show the similar effects, which indicated that the influence depends on the mode of the bioturbation $[15,26]$.In addition, macroinvertebrate activity may alter flow paths in the interstitial spaces [27].

Tubificids, one of the representative bioturbation invertebrates found commonly in river system, was chosen as the subject of our research $[17,28,29]$. As a dominant group of benthic macroinvertebrates, tubificid worms can survive in the contaminated river system and even thrive in organic-rich sediments [30]. With a relatively high resistance to polluted environment, they are commonly the last taxon that disappears in polluted water bodies, thereby viewed as a representative indicator species of freshwater [31,32]. Because tubificid worms live on the SWI and are in directly contact with both solid phase and liquid phase, their bioturbation undoubtedly influences hydrological processes near the SWI, including the exchange of surface water and pore water. Tubificids, widespread in freshwater, exhibit variation in density, which can be as high as $10^{5}$ individual $/ \mathrm{m}^{2}$ [3]. Although previous studies have estimated the water flux affected by tubificids, the range of biological density and the duration of bioturbation were not factored in, which is a limitation in reflecting the diversity variation of the tubificid density in the natural environment [22].

Therefore, it is necessary to clarify the link between the tubificid density and the vertical water exchange across the SWI. A density gradient is conducive to elucidating the impact of bioturbation on the vertical water exchange, while shedding light on the spatiotemporal heterogeneity of local water exchange. Additionally, the observation of flow paths in sediment affected by hyporheic organisms was insufficient in previous studies carried out in small columns $[15,22]$. Thus, in our research, laboratory experiments with flumes were performed to observe and quantify the bioturbation-induced water exchange under different biological densities [33]. The survival time of tubificid worms is generally about 80 days, during which period, the bioturbation effect will always exist. However, our purpose of choosing duration as a variable is more focused on observing the response of water exchange to the cumulative time of bioturbation, rather than the changes in water exchange throughout the whole life of tubificid worms. Besides, when the worms were used in the formal experiment, they had survived for a certain period. Finally, the experimental period was selected as 21 days based on previous studies [22,34]. In this study, the vertical water exchange includes two aspects, namely, the vertical water flux (VWF) and the maximum penetration depth. Objectives of this study are to (1) estimate 
VWF induced by tubificid bioturbation with different density; (2) gauge local-scale penetration depth into the bed induced by tubificid bioturbation with different density. A series of salt and dye injection experiments were conducted under different density conditions in laboratory circulating flumes with a flat sand bed over 21 days. This study has implications for better understanding the contribution of tubificid bioturbation on the river ecosystem.

\section{Materials and Methods}

\subsection{Flume Design}

Experiments were conducted in 14 recirculating laboratory flumes over 21 days to investigate the impact of tubificids on vertical water exchange across the SWI. The recirculating flume has been considered as a convenient device in the studies of hyporheic water exchange, enabling the observation of exchange processes through the transparent glass, and allowing the measurement of conservative tracer transferring from surface water to pore water, as it is a closed system [10,35]. The specific flumes used in our research were set up as $0.7 \mathrm{~m}$ long, $0.15 \mathrm{~m}$ wide, and $0.5 \mathrm{~m}$ high (Figure 1 ).

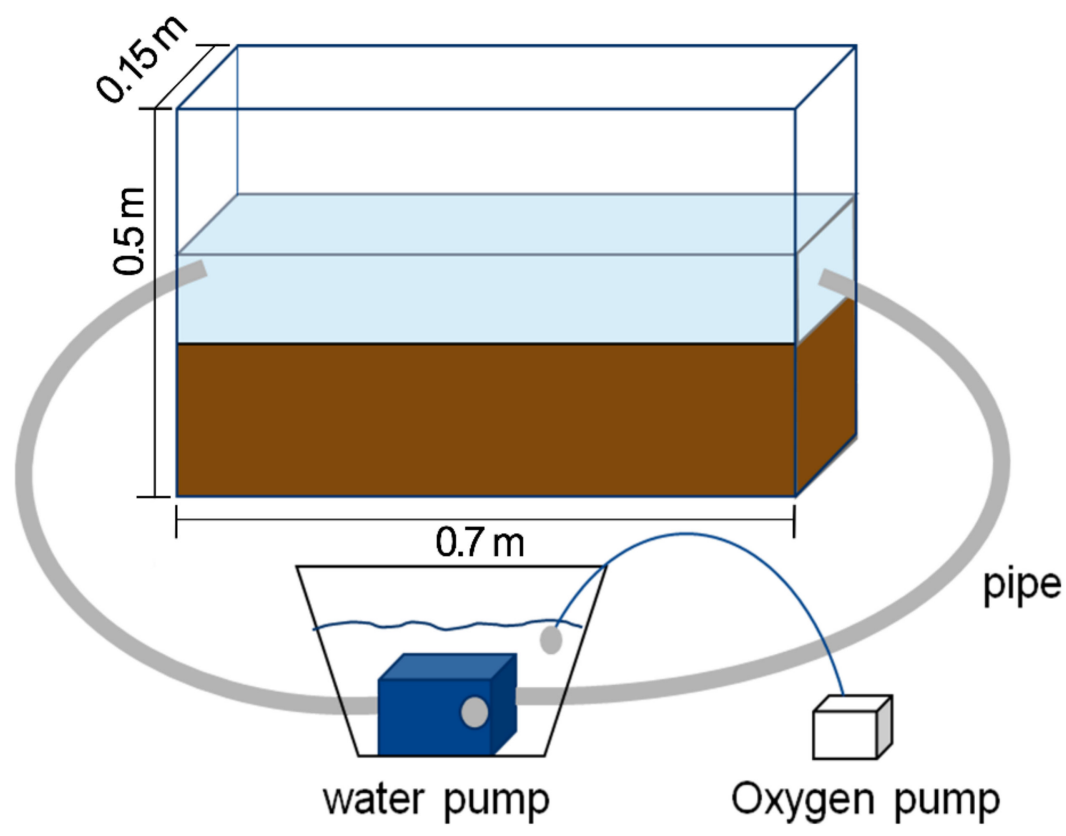

Figure 1. Single flume device designed in the experiment.

Each flume was evenly filled with $0.2 \mathrm{~m}$ thick sediment and $0.1 \mathrm{~m}$ deep overlying water collected in situ from the junction of Jue River and Hao River ( $\mathrm{Xi}^{\prime}$ an, China, $\left.34^{\circ} 7^{\prime} \mathrm{N}, 108^{\circ} 53^{\prime} \mathrm{E}\right)$. The overlying water was set and precipitated to eliminate large impurities and debris. The sediments were collected from surficial (upper $20 \mathrm{~cm}$ ) sediment in situ through transparent PVC pipe and then transported back to the laboratory for air drying. Particles larger than $0.5 \mathrm{~mm}$ that are not suitable for the survival of tubificids are removed by sieving and then the sediments were fully mixed to ensure a homogeneous composition in each flume. The mixed sediment was placed in flumes and manually smoothed to a flat bed. Surface water in each flume was circulated by a circulating pump to ensure a constant flow rate and a stable sand bed condition. The oxygen delivery pipe and water circulating pump were placed in a water tank for each flume. No influx water exists in the relatively closed system except for a small amount of water added to the water tank to replenish the water lost by evaporation. During the whole experiment, the temperature and natural indoor light were basically constant. In order to better simulate the dark conditions of the natural river bed, we covered flume walls with tin foil (removed only when taking pictures). 


\subsection{Experimental Setup and Data Analysis}

Due to the complexity of the devices and the multiple comparison conditions, seven treatments were used in this experiment, including one control and six different densities, in duplicates. Tubificid densities in seven treatments were $0,5,10,15,20,25$, and 30 individual $/ 10 \mathrm{~cm}^{2}$, respectively, according to the range of natural density of the Wei River [36]. One treatment has two parallel flumes (i.e., Flume 0 and Flume $0^{\prime}$ are parallel flumes with a density of 0 individual $/ 10 \mathrm{~cm}^{2}$ ). All flumes were run for 7 days before the introduction of worms (day 0 ) in order to obtain a stable water sediment system. The tubificid worms were obtained from a commercial source due to insufficient number of worms in the collected sediment. The obtained worms were precultured in laboratory conditions simultaneously for acclimation [22]. We calculated the number of worms required for each flume according to the set density, and picked worms artificially with tweezers. Tubificid worms were added to the flumes with the circulation pump turned off, to prevent them from being washed into the pipes. The worms were directly added into the overlying water and after all worms burrowed into sediment the circulation pumps were turned on. The tubificid worms spontaneously dispersed on the sediment surface within a few minutes, and distributed uniformly after $40 \mathrm{~min}$. Dead worms would float on the surface of the overlying water [34]. During the experiment, no tubificid worms were found in the overlying water. The changes in the structure of the sediment were observed through the transparent glass wall of the flume. The VWF was estimated by salt injection experiment on days $0,7,14$ and 21 . Physicochemical parameters (temperature, $\mathrm{pH}$, dissolved oxygen, and velocity) were measured using a portable water quality meter (HQ40d, HACH, U.S.) and a portable flow meter (MGG/KL-DCB, ZhuoMai, China) in overlying water on day 0 , day 7 , day 14, and day 21 to ensure consistent physical conditions in all flumes [22]. The measured values are all the mean \pm standard deviation (SD) of the two replicates in same treatment at each sampling time [34]. The effects of tubificid density and experiment duration on the VWF and $\triangle \mathrm{VWF}$ were estimated by repeated measures analysis of variance (RM-ANOVA), followed by the least significance difference (LSD) test using Statistical Package for the Social Sciences (SPSS) 17.0 software.

\subsection{Salt Injection Experiment}

The VWF was calculated by the vertical discharge model of [37] on days $0,7,14$, and 21, using sodium chloride $(\mathrm{NaCl})$ as a conservative tracer. The adaptation of the tubificid worms to the salt concentration was tested before the experiment to ensure the salt concentration used in the experiment will not affect the survival of worms. A $\mathrm{NaCl}$ solution, prepared by adding $2 \mathrm{~g}$ reagent-grade salt to $50 \mathrm{~mL}$ water, was slowly injected into the surface water at a constant rate during one flume circulation period (about $10 \mathrm{~s}$ ) to obtain well-mixed initial surface water with $\mathrm{NaCl}$ [10]. This initial concentration was obtained by dividing the mass of solute tracer $\mathrm{NaCl}$ by the solution volume (including volume of surface water and pipes). Based on our preliminary experiment, $\mathrm{NaCl}$ was distributed evenly in the surface water after about $10 \mathrm{~s}$. A portable water quality meter (HACH HQ40d) connected with a $\mathrm{NaCl}$ probe (cdc40101) was used to monitor salt concentrations in the water column. The probe was put in to the overlying water and the measurement continued until the salt concentration was constant. The concentration time series, which were used to calculate the VWF, were obtained by recording the salt concentrations at 5-s intervals. During the 21-day experiment, the salt injection experiment was carried out at 7-day intervals in each flume. The calculation of VWF followed the vertical discharge model from [37] based on mass balance:

$$
\begin{gathered}
C_{s}(t)=\left(C_{s}[t=0]-C_{e q}\right) e^{\left(-\frac{\left.\mathrm{Qt}_{\mathrm{s}}+\mathrm{V}_{\mathrm{p}}\right\rfloor}{\mathrm{V}_{\mathrm{s}} \mathrm{V}_{\mathrm{p}}}\right)}+C_{\mathrm{eq}} \\
\mathrm{V}_{\mathrm{p}}=\frac{\mathrm{V}_{\mathrm{s}} \times \mathrm{C}_{\mathrm{S}}[\mathrm{t}=0]}{\mathrm{C}_{\mathrm{eq}}}-\mathrm{V}_{\mathrm{s}}
\end{gathered}
$$


where $\mathrm{Q}\left(\mathrm{m}^{3} / \mathrm{s}\right)$ is the VWF rate; $\mathrm{Cs}(\mathrm{mg} / \mathrm{L})$ is the tracer concentration in the surface water; Ceq $(\mathrm{mg} / \mathrm{L})$ is the equilibrium tracer concentration; $t$ is the time; vs. $(\mathrm{L})$ is the volume of surface water; $\mathrm{Vp}(\mathrm{L})$ is the volume of sediment pore water.

Using this model, we fitted the mass balance equation to the measured concentration time series to obtain the vertical water flow rate (Q). VWF in every flume was calculated by dividing the vertical water flow rates by the sediment surface area. Subtracting the initial VWF value (measured on day 0 ) from the VWF values measured on days 7, 14, and 21, respectively, we obtained the changes of VWF $(\triangle \mathrm{VWF})$ on these three days. The value of the $\triangle \mathrm{VWF}$ corresponds to the role of tubificids on water flux, a positive value indicating the effect of promotion, and negative value the effect of inhibition.

\subsection{Dye Injection Experiment}

Dye injection experiments were performed to visualize the flow paths of surface-pore water exchange. A non-reactive dye (FD\&C Blue No. 1) was dissolved in water to obtain a solution of the desired color for the observation of clear blue trajectories from the side wall of the flumes. To prevent the dye solution from passing off by turbulent diffusion occurring at the near-interface, we injected it at a location $2 \mathrm{~cm}$ below the bed surface [38]. Outline of dye trace was recorded continuously by marker pen because the trace would fade in color with time (Figure 2). The D $p_{\max }$ was characterized as vertical distance from the SWI to the deepest location that trajectory reached in sediment. Decrease of the $D p_{\max }$ means the deepest location moved close to the surface, and vice versa. To investigate the effect of biological density on the $D p_{\max }$, the dye was injected twice at the same position before and after the introduction of tubificid worms (day -5 and day 22), and then continuously delineated to obtain the flow paths. The difference between the two D $p_{\max }$ values measured before and after 21-day experiment period (the latter minus the former) was marked as $\Delta \mathrm{Dp}_{\max }$. Since the dye was injected at the same location of the sediment before and after the bioturbation, this almost guaranteed that the result was not affected by factors other than bioturbation. In this way, the difference between the two maximum depths is only caused by the bioturbation. Thus, one measurement of penetration depth was performed per density.
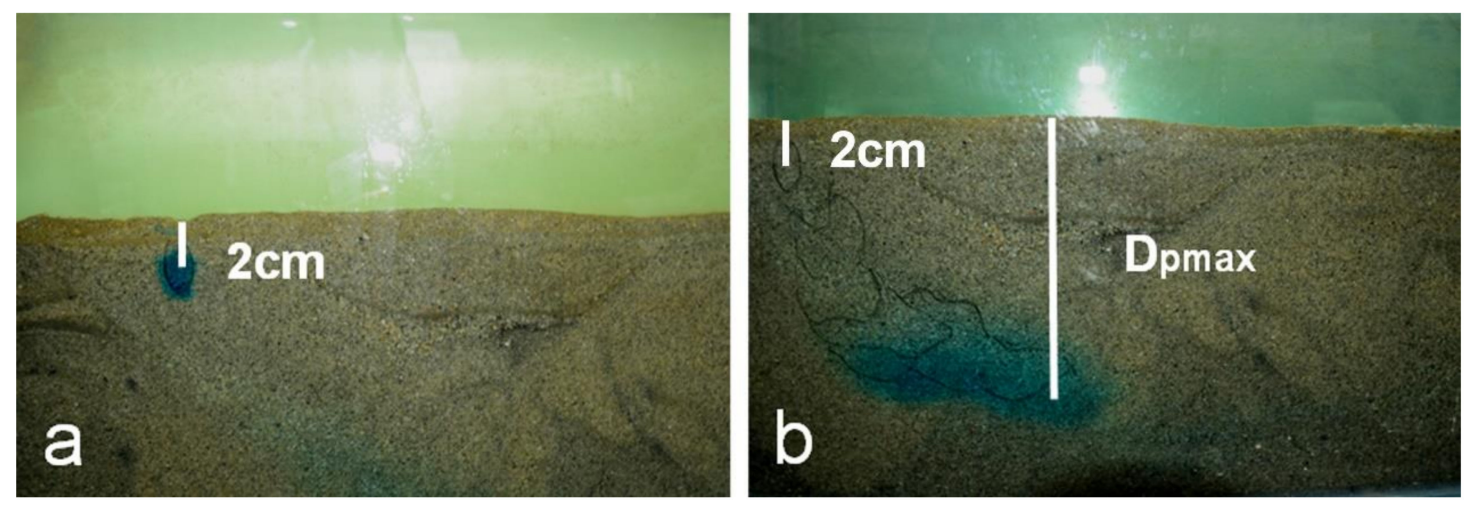

Figure 2. Flow path depicted on the flume wall, (a) distance from the dye injection point to the bed surface; (b) distance from the maximum penetration point to the bed surface. Here, one of the seven flumes for dye injection experiment was taken as an example.

\section{Results}

\subsection{Visual Observation of Tubificids Activity}

On day 0 , tubificid worms were added into flume 1 to flume 6 , spontaneously dispersed on sediment surface and dug into the sediment, which may be a migration behavior to ensure sufficient living space and food. 
At the end of the experiment, plenty of lateral galleries appeared in the surficial sediments of flume 1 to flume 4 with low-density (Figure 3a,b), while fewer lateral channels were formed in flume 5 and flume 6 with high-density, and part of the worms became vertically dwelling as a cluster in the sediment (Figure 3c,d).
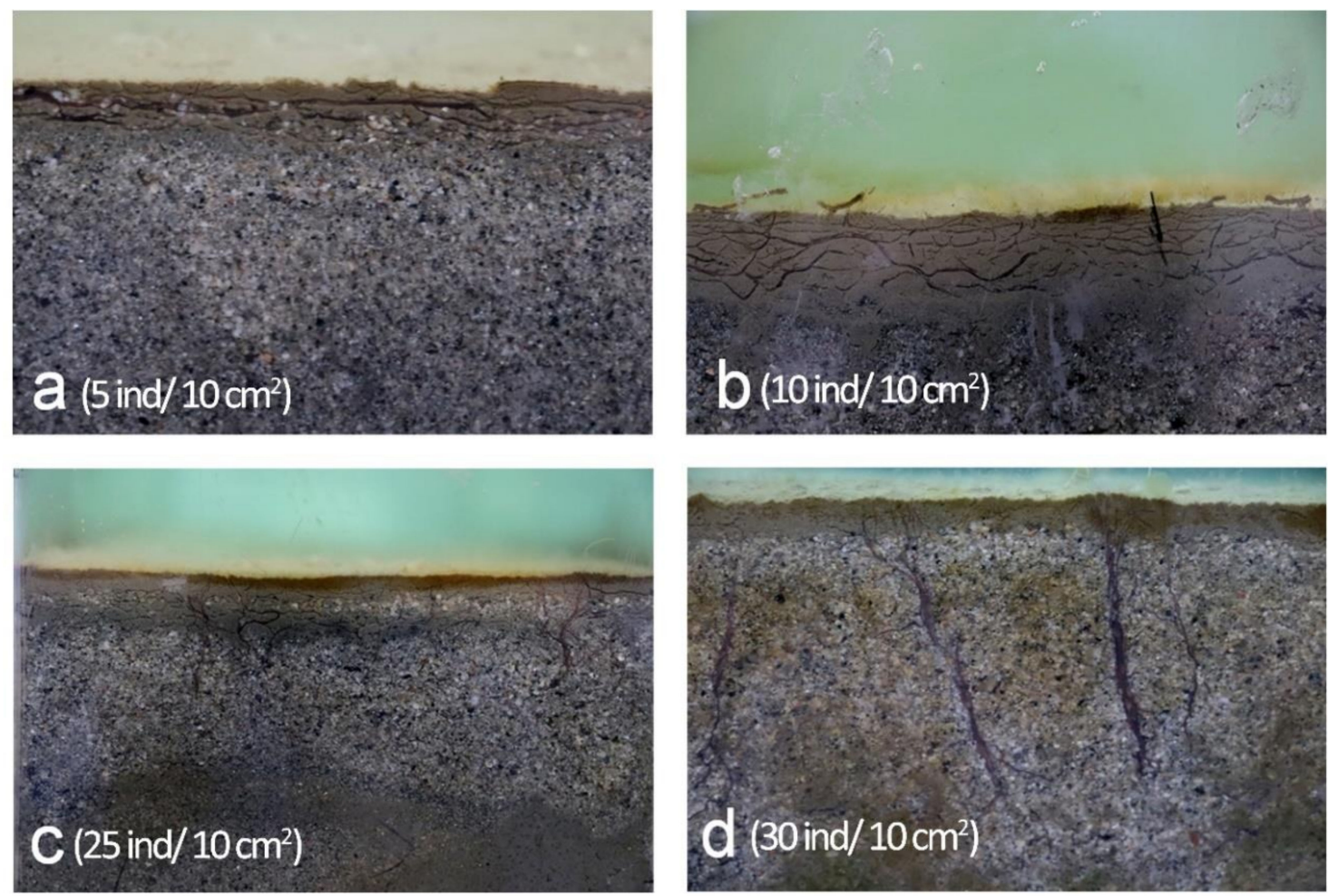

Figure 3. Activity and distribution of tubificid worms in different densities ((a) flume 1; (b) flume 2; (c) flume 5; (d) flume 6).

\subsection{Physical Features Variation of the Sediment-Water System}

During the 21-day experiment period, the water temperature was maintained at a range suitable for tubificid worms $\left(24.8 \pm 4{ }^{\circ} \mathrm{C}\right)$ and the temperature of each group is the same every day. Dissolved oxygen $(8.52 \pm 0.51 \mathrm{mg} / \mathrm{L})$ remained stable and consistent throughout the experiment as the oxygen pump provided sufficient oxygen for each flume. Flow velocity $(0.069 \pm 0.012 \mathrm{~m} / \mathrm{s})$ was controlled by the same pump and device to maintain a consistent rate.

Prior to the introduction of tubificids, the sediment surface was smooth and flat in all flumes due to the 7-day cycle and stabilization processes of the sediment-water system. A fine layer formed in each flume by continuous precipitation of small particles from the overlying water, and then became uniform and flat under the scouring of the water flow.

On day 21, minute changes were identified on the sediment surface in the control flume, while the fauna flumes were altered to varying degrees by tubificids of different densities. The most visible consequence of bioturbation on the surficial sediment was the appearance of holes and galleries with increasing density of tubificid worms. The overview of the SWI revealed obvious holes, with diameters of approximately 0.5 to $2 \mathrm{~mm}$ in the fauna flumes (Figure 4). Large and sparse holes appeared on rough sediment surface in fauna flume 1,2,3 (with density of 5,10,15 individual/10 $\mathrm{cm}^{2}$ ), which were unevenly distributed due to the randomness and irregularity of biological activities. However, in high-density flume 5 and flume 6 (with density of 25 and 30 individual/10 $\mathrm{cm}^{2}$ ), small and dense holes were present on the relatively smooth and flat sediment surface, while the sediment surface in fauna flume 4 (20 individual/10 $\mathrm{cm}^{2}$ ) was relatively rough with dense holes. The sediment surface of fauna flumes was generally rougher than the control flume. The roughness of sediments in flumes with 
different biological densities is as follows: low-density fauna flumes $\left(5,10,15\right.$ individual $\left./ 10 \mathrm{~cm}^{2}\right)$ $>$ high-density fauna flumes $\left(20,25,30\right.$ individual $\left./ 10 \mathrm{~cm}^{2}\right)>$ control flume $\left(0\right.$ individual $\left./ 10 \mathrm{~cm}^{2}\right)$ (Figure 4). Simultaneously, the thickness of the settled layer in the control flume hardly changed based on the observation through the transparent glass wall of the flume. However, in all fauna flumes, the fine layer thickness increased significantly with higher densities (Figure 5).

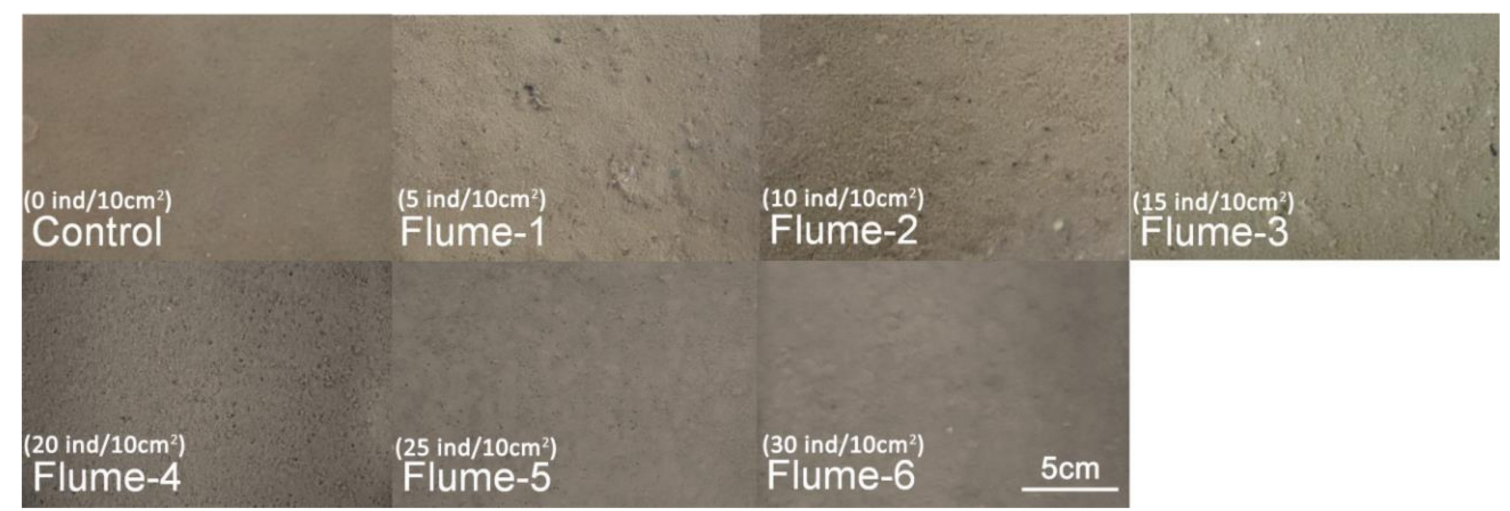

Figure 4. Effect of bioturbation on the sediment surface under seven biological densities.

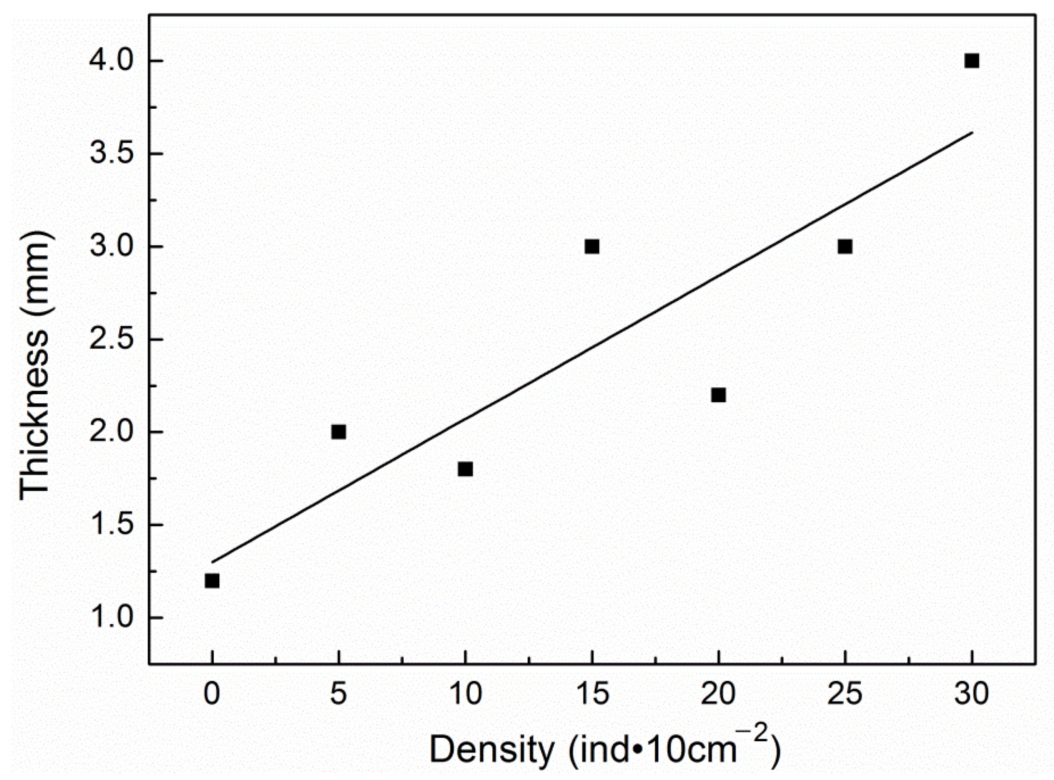

Figure 5. Thickness of fine sediment layer under seven biological densities.

\subsection{Dynamic Changes of Vertical Water Flux}

On days $0,7,14$, and 21 , concentration time series in each flume was measured respectively. The decreasing of salt concentration in the overlying water was identified in all flumes, indicating that the salt-sufficient surface water exchanged with the sediment pore water. The tracer concentration in all flumes showed a continuous decline followed by a constant state (Figure 6). On day 0, before the addition of tubificid worms to the fauna flumes, the values of the initial VWF ranged from 0.19 to $0.34 \mathrm{~L} \cdot \mathrm{m}^{-2} \cdot \mathrm{s}^{-1}$. On days 7,14 and $21, \mathrm{VWFs}$ were measured again. The VWF values of both control and fauna flumes did not exhibit a continuous increase during the 21-day experiment period (Figure 7).

The results of RM-ANOVA analysis showed a significant difference in VWF among different density treatments $(\mathrm{df}=6, \mathrm{~F}=15.476, p=0.001)$. The interaction effects between time and each density treatment are significantly different $(\mathrm{df}=9.984, \mathrm{~F}=12.048, p<0.001)$, indicating that under different biological densities, the changes of VWF with time vary. The results of RM-ANOVA analysis also showed that there was a significant difference in $\triangle \mathrm{VWF}$ between different density treatments $(\mathrm{df}=6$, 
$\mathrm{F}=16.967, p=0.001)$. Simultaneously, the interaction effects between time and each density treatment are significantly different $(\mathrm{df}=12, \mathrm{~F}=10.358, p<0.001)$. The VWF of the control flume and fauna flumes 1, 2, 3, and 4 reached maximum values on different days, while the fauna flume 5 and flume 6 showed a decreasing trend, compared with the value measured on day 0 (Figure 7 ). The $\Delta$ VWF values of the control flume and the low-density flumes 1,2,3, and 4 were positive, while the high-density flume 5 and flume 6 showed negative values (Figure 7). Particularly, flume 2 and flume 4, with the highest overall level of $\Delta V W F$ among all flumes, reached their maximum $\Delta V W F\left(2.12 \pm 0.94 \mathrm{~L} \cdot \mathrm{m}^{-2} \cdot \mathrm{s}^{-1}\right.$ and $2.10 \pm 0.42 \mathrm{~L} \cdot \mathrm{m}^{-2} \cdot \mathrm{s}^{-1}$ ) on day 14 and day 7 , respectively. On day 21 , all flumes showed negative $\Delta$ VWF values, except for flume 2 . Nonetheless, VWF of flume 2 exhibited a clear downward trend.

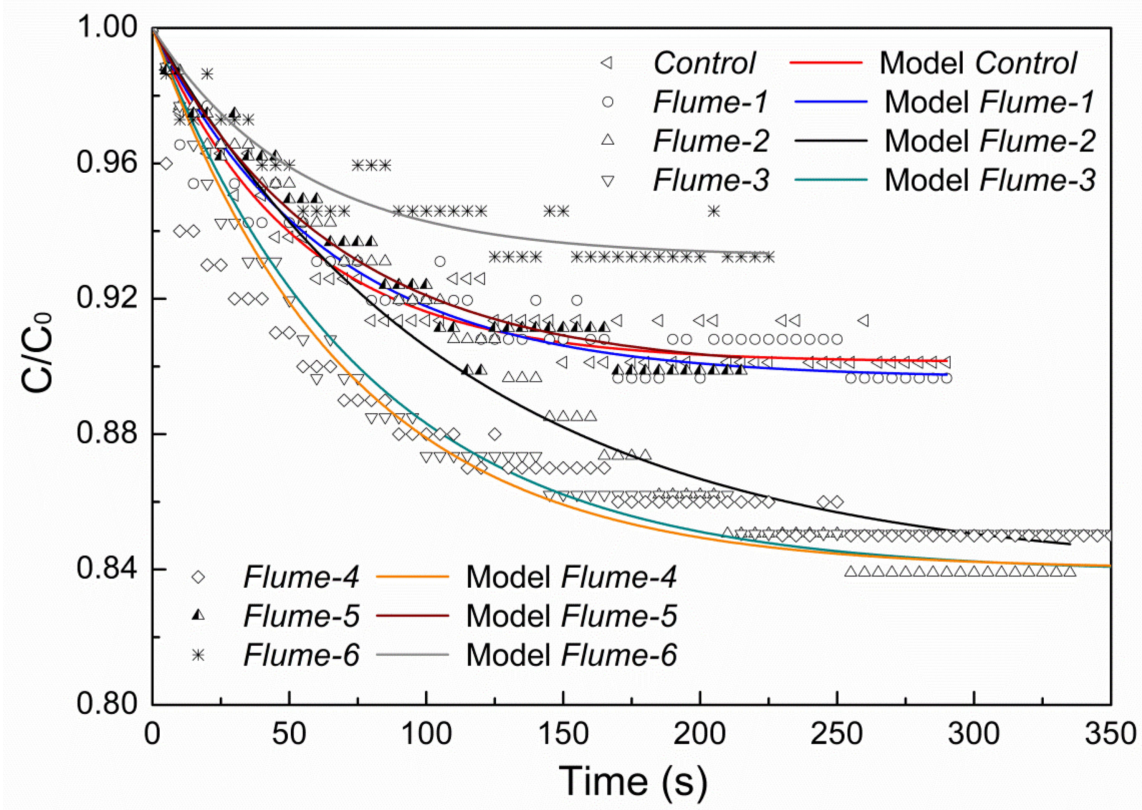

Figure 6. Concentration-time curves monitored (symbols) and fitted (lines) under seven biological densities. Here, one of the parallel groups measured on day 0 was taken as an example.

Overall, within a low-density range (less than or equal to 20 individual/10 $\mathrm{cm}^{2}$ ), the tubificid bioturbation increased the volume of vertical water exchange at the SWI over a period of time. This enhancement was most intense at a density of about 10 and 20 individual $/ 10 \mathrm{~cm}^{2}$, especially at 20 individual $/ 10 \mathrm{~cm}^{2}$, in which the VWF increased for a longer time and reached its maximum value at a later time. However, when the density exceeded (or equaled) 25 individual $/ 10 \mathrm{~cm}^{2}$, the presence of tubificid worms weakened the water exchange. When the tubificid disturbance persisted until day 21 day, the worms exerted negative effect on VWF, regardless of density.

\subsection{Variation of Maximum Penetration Depth}

Through the trajectory observation, a situation similar to that described by Packman et al. (2004) was found. Above the injection point, a portion of the dye diffused upward into the surface water. Simultaneously, the dye moved horizontally in the sediment bed. There was an upward diffusion at approximately $20 \mathrm{~cm}$ horizontally from the injection point. The dye diffused above the bed surface, which was caused by the turbulent diffusion. The dye trajectory showed signs of turbulent mixing within a few centimeters above the bed (observed by the movement of blue dye above the injection point).

The maximum penetration point dropped the most in the control flume, where a decrease in the $D p_{\max }$ (from 15 to $8.5 \mathrm{~cm}$ ) was identified after the 21-day experiment period (Table 1). The $\Delta \mathrm{D} \mathrm{p}_{\max }$ increased with the increasing density of tubificid worm, and further transformed to a positive value when the density was greater than or equal to 20 individual $/ 10 \mathrm{~cm}^{2}$. Such trend indicates that, 
the bioturbation enhanced $D p_{\max }$, which intensified with increasing density, though the relationship is not linear (Figure 8).
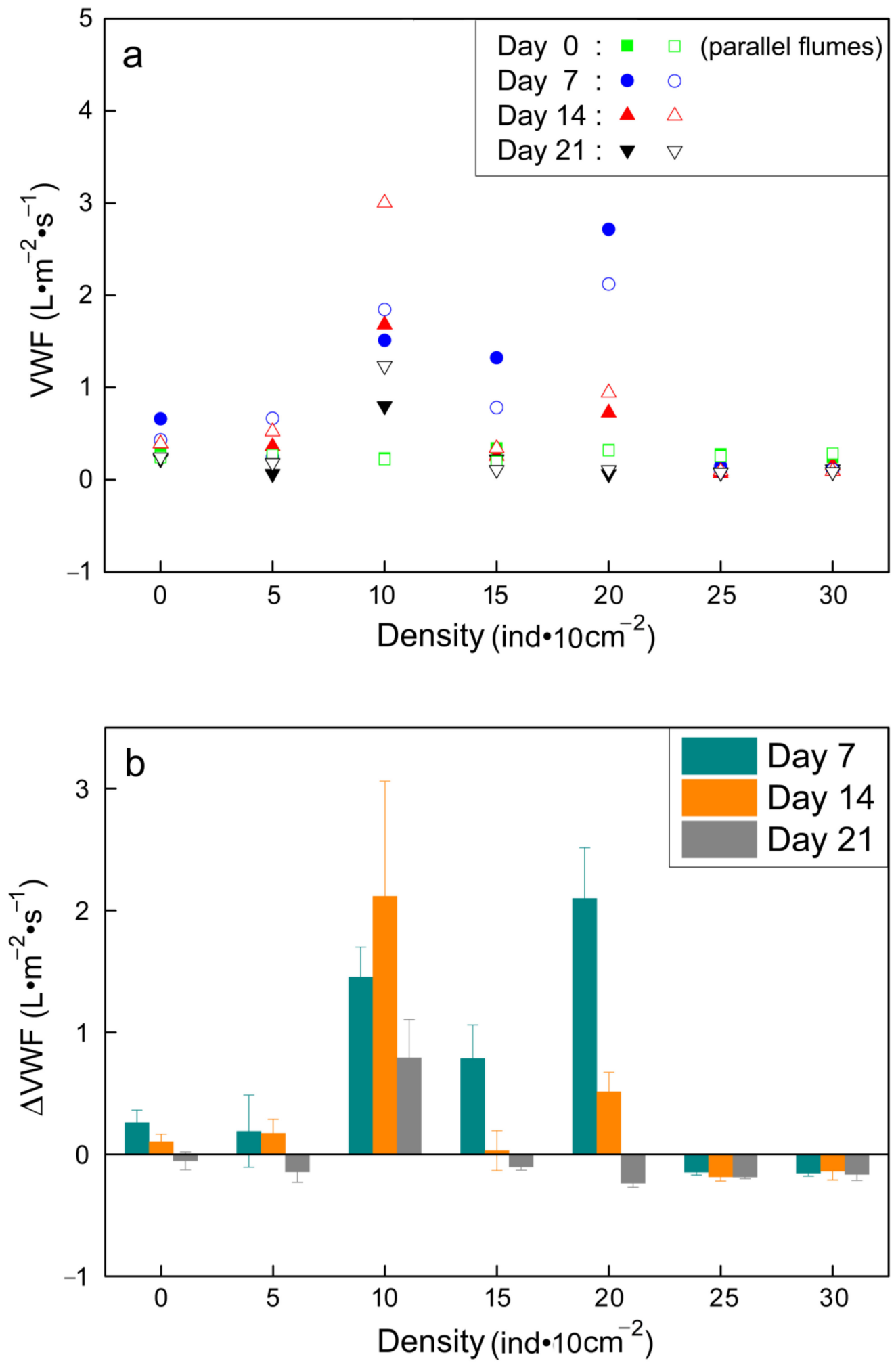

Figure 7. Changes of vertical water flux (VWF) and $\triangle$ VWF with 7-day intervals under seven biological densities ((a) VWF and (b) $\Delta \mathrm{VWF).} \mathrm{Each} \mathrm{density} \mathrm{treatment} \mathrm{has} \mathrm{two} \mathrm{parallel} \mathrm{flumes.} \mathrm{The} \mathrm{presented}$ vertical water fluxes in (b) are the mean \pm standard deviation (SD) of the two parallel groups in each density treatment at each measurement day. 
Table 1. The penetration depth measured before and after 21-day bioturbation period under seven biological densities.

\begin{tabular}{cccc}
\hline Treatment & Density (Individual/10 $\mathbf{~ c m}^{\mathbf{2}}$ ) & \multicolumn{2}{c}{ D $\mathbf{p}_{\max } \mathbf{( c m )}$} \\
\hline & & Day $\mathbf{- 5}$ Inject & Day 21 Inject \\
\hline Control & 0 & 15 & 8.5 \\
Flume-1 & 5 & 11.9 & 9.7 \\
Flume-2 & 10 & 15.6 & 12 \\
Flume-3 & 15 & 11.8 & 8.1 \\
Flume-4 & 20 & 8.6 & 10.5 \\
Flume-5 & 25 & 11.5 & 15.6 \\
Flume-6 & 30 & 8.7 & 12 \\
\hline
\end{tabular}

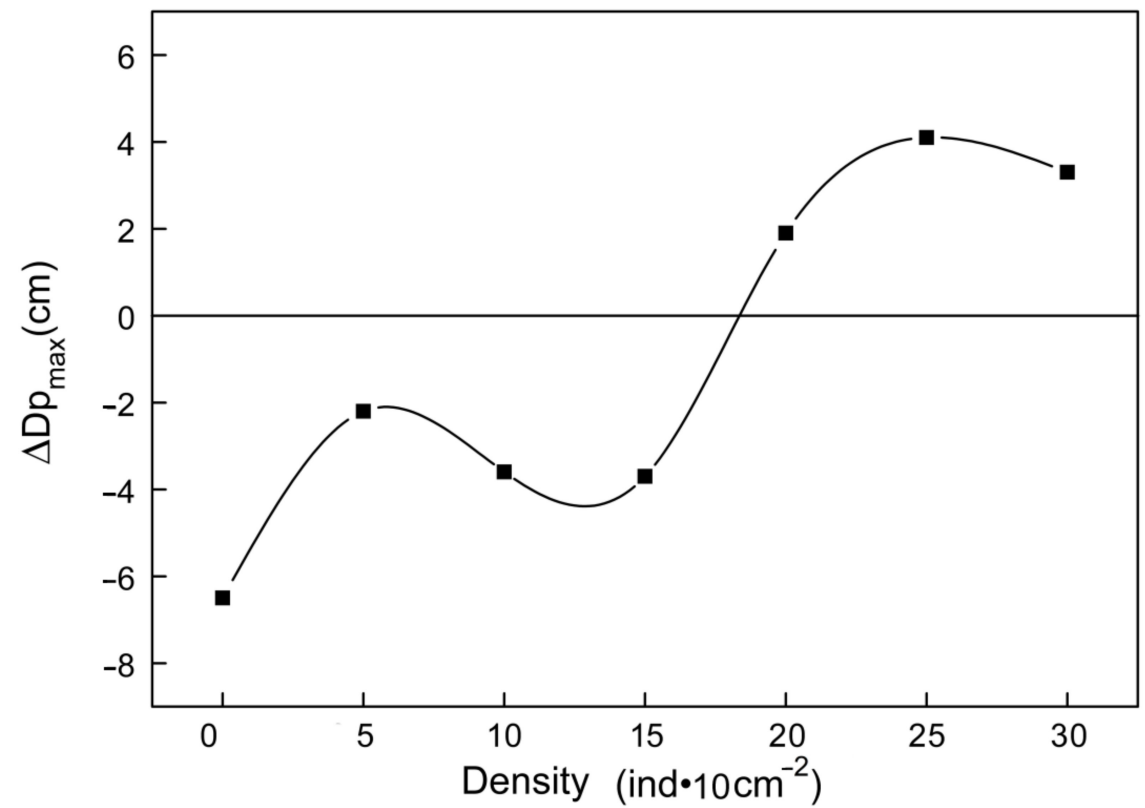

Figure 8. Changes of the $\mathrm{D} \mathrm{p}_{\max }$ induced by bioturbation under seven biological densities. Its positive or negative corresponds to the increasing or reducing trend compared with the initial $\mathrm{Dp}$ max before the introduction of tubificids.

\section{Discussion}

\subsection{Biological Behavior and the Sediment-Water System}

As stated in past studies, the biological behavior of tubificid worms changes the structure of sediments $[19,20]$. Obvious changes were identified in surficial sediment after 21-day bioturbation. These phenomena are of great significance for interpreting worm effects on the intensity and depth of the water exchange at the sediment-water interface. In addition to the changes of the settled layer caused by the precipitation of fine particles in the overlying water, the modulation of the sediment by tubificids contributed to the smaller particle size in surficial sediment. Dafoe et al. [39] found that dense populations of tubificid worms can efficiently modulate bottom sediments by selective ingestion of silt and clay. Tubificid worms burrow their heads into the deep layers of sediments and ingest the surrounding organic matter $[28,29]$. Undigested food is excreted in the form of fine particles from the waving tail exposed above the sediment, settling randomly, thus, a layer of mucus-bound fecal pellets appears above the sediment surface [30]. Simultaneously, the top layer of sediment moved down slowly toward the feeding zone in the deep layer sediment around the worms [28]. Thus, sediment displacement and mixing occurred, leading to changes of microtopography at surficial sediment across the SWI $[34,40]$. 
Tubificid worms continuously created new burrows and pathways, consequently, modifying the structure of surficial sediment and, thus, the dispersion of the water flux in the sediment [23]. The impact of worms on sediment mainly occurs in the upper layer $(0-10 \mathrm{~cm})$ as past studies reported, which explains the range of worm activities [41]. However, in a natural river channel, the depth of sediment is greater than that in the experiment, and the effects of various organisms are not restricted to the upper $10 \mathrm{~cm}$ of streambed. Such effects may be more complex and extensive, which have more profound impacts on the sediment structure and water exchange. It is necessary for future research to further explore the biological behavior and sediment structure changes affected by different organisms at varying depths.

\subsection{The Response of Vertical Water Flux to Tubificid Density and Experiment Duration}

Although all flumes with flat beds were free of fauna on day 0 , exchanges between surface water and pore water existed. Verified by the trajectory obtained from the dye tracer experiment, Packman et al. [35] proved that vertical advective flow occurs along with horizontal pore water flows in the flat bed. The obtained turbulent diffusion and advection along the well-defined flow path (observed by the movement of dye) were explained by flow separations induced by slight irregularities of the bed surface (related to particle size and arrangement), providing sufficient head differences to drive advective pumping flows [35,42,43]. In low-density flumes $\left(5,10,15\right.$ individual $\left./ 10 \mathrm{~cm}^{2}\right)$, obvious horizontal galleries appeared within the upper $5 \mathrm{~cm}$ of the sediment, caused by the active horizontal movement of tubificid worms as the width of the galleries were the same as the width of the worm body. Under suitable living conditions with ample food and sufficient space, the tubificid worms tend to explore actively to obtain more available resources in the shallower sedimentary layer [40]. In addition, the sediment was relatively loose in shallower layers, which is conducive to high oxygen levels and the survival and feeding of organisms. Meanwhile, the waving of the posterior end of worm bodies in the water reduced the sediment on the top of the hole, gradually enlarging the surface holes [36]. The formation of large holes and galleries leads to enhancement in the sediment porosity and, thus, VWF. However, the formation of a fine layer due to worm feeding and excretion potentially lowers the VWF. Song et al. [36] deemed that, with the increase of tubificid density, the percentage of coarse sand and fine sand decreases and the content of floating mud increases, which may decrease the VWF by altering the composition of the sediment. Nonetheless, the large holes and galleries formed by the active movement of the tubificid worms increased the water exchange, which plays a more significant role compared to fine layer and, thus, a positive consequence on VWF was yielded by tubificid bioturbation.

Under high biological densities $\left(20,25,30\right.$ individual $\left./ 10 \mathrm{~cm}^{2}\right)$, the holes were enlarged and affecting each other (overlapping), and eventually too dense to be independent. Disturbances of massive worms caused weak stability of surface holes, preventing the formation of larger holes in the surface layer, thus exhibiting relatively smooth surface [36]. In flume 5 and flume 6 ( 25 and 30 individual $/ 10 \mathrm{~cm}^{2}$ ), worms dug vertically into the upper $10 \mathrm{~cm}$ sediment, with hardly lateral movement in the shallow layers. The vertical movement mode can be explained by an adaptive response to a lack of living resources. An " $n$ " type relationship between biological migration and density (the migration rate first increased and then decreased with the increase of density) was identified when the density is less than 40 individual $/ 10 \mathrm{~cm}^{2}$ [44].

Under the high-density scenario, organisms avoid energy consumption in response to food shortages by reducing migration [44]. In addition, reducing lateral movement in relatively small space can prevent worms from interfering with each other. Thus, the lack of survival resources caused by high-density may hinder the migration of organisms, resulting in almost no further formation of holes and galleries [44]. Moreover, the large number of worms digging into the sediment may lead to soil clogging, negatively affecting the volume of the vertical water exchange at the benthic interface.

Furthermore, the permeability of the sediment was lowered by the accumulation of fecal pellets above the initial sediment (basically increased with increasing density) [29]. In the meantime, 
the intensity of the disturbance diminishes after the worms have adapted to the environment [34]. These two factors jointly weakened the water exchange across the SWI, causing negative $\triangle$ VWF values at all densities on day 21 .

\subsection{The Response of Maximum Penetration Depth to Tubificid Density}

The comparison of the variability of $\mathrm{Dp}_{\max }$ under different biological densities revealed that the presence of worms increased the depth at which surface water can enter the sediment. In the flat bed of this experiment, surface-interstitial water exchange occurred near the SWI, by a combination of advective pore water flow and turbulent diffusion caused by the heterogeneity of sediment features, such as the irregular particle size arrangement [35]. During the 21-day experiment, the sediment particles on the benthic interface were constantly disturbed and reworked by tubificid worms. Moreover, undulating motion of the posterior end of worms for respiration contributes to turbulent mixing across the SWI $[35,45]$. Although not a linear change, this increase effect on $D p_{\max }$ is more obvious at large density within the range of natural density of tubificid worms, which was not consistent with the results of VWF. The possible explanations for the $\mathrm{Dp}_{\max }$ becoming deeper with the increase of tubificid density were given: (1) as mentioned above, the undulating tail of the tubificid worms caused the surface mud to be resuspended and resettled, decreasing the diameter of holes, thus, more smaller holes were observed, instead of large holes on the surface of the sediment. Nevertheless, the galleries formed by a large number of tubificid worms in the sediment still existed. (2) As mentioned above, under the condition of high tubificid density, there are relatively more vertical galleries, while under the condition of low tubificid density, there are more horizontal galleries. We suspected that the direction (lateral or vertical), the shape, and the number of the galleries, will all affect the penetration depth of surface water into the sediment. Vertical galleries may be more conducive to the penetration than lateral galleries. Additionally, given that additional factors may contribute to the sediment surface irregularity, and the interstitial flow path were not factored in this study, the interpretation of the related processes under multiple factors will be further explored in future research.

The effect of tubificid worms on $\mathrm{D} \mathrm{p}_{\max }$ may affect the material circulation and metabolism near the riverbed interface. The increase of $\mathrm{Dp}_{\max }$ enhances the space range of water exchange, where biochemical and physical reactions occur. Such an increase may allow easier oxygen and nutrients transport from overlying water to the bottom sediment layer, leading to positive effects for activity of the hyporheic zone. Overall, when the density of tubificid worms is 20 individual/10 $\mathrm{cm}^{2}$, the extent of water exchange is the largest, and the reachable exchange position is relatively deep, which means the intensity of hyporheic exchange, as well as the spatial range where the physiochemical reaction and metabolism may take place, were all at a high level.

Our research found that the greater the density, the greater the penetration depth. In the case of such a high density, for the polluted river section, pollutants may enter deeper sediments, and different organisms in the sediments at different depths may play different roles. However, the accumulation of pollutants in shallow sediments may be easier to turn back to the surface water. When the density is 20 individual/10 $\mathrm{cm}^{2}$, the exchange of pollutants accompanying water exchange may be more conducive to river water health. Perhaps, in river management, we control the discharge of pollutants so that the density of worms in the water body reaches a certain medium level. The bioturbation is beneficial to the reduction of pollution concentration and is beneficial to the self-purification of the river.

\subsection{Implication}

Despite the established belief that the tubificid bioturbation is beneficial to the VWF, in this study, it was found that when the density is too high (greater than 20 individual $/ 10 \mathrm{~cm}^{2}$ in this study), the bioturbation may hinder the water exchange process at the streambed.

Tubificid worms prefer to live in fine sandy riverbed, which is conducive to their feeding and migration. Clogging is more likely to occur in a fine sandy riverbed than a cobblestone, gravel, or coarse 
sandy riverbed. The presence of tubificid worms will aggravate or alleviate the clogging of the fine sandy river bed, which is important to the health of the river ecosystem (enhanced or weakened water exchange may mean whether the polluted surface water can exchange with pore water, thereby being bioutilized and decomposited).

High-density worms are prone to appear in rivers with heavy pollution and eutrophication, hindering the exchange of water, worsening the already polluted river. With limited function of river self-purification, the biological utilization and decomposition of pollutants is conducive to river water purification. Controlling the discharge of river pollution has largely prevented the production of high-density worms, thereby preventing more severe effects. In areas with low pollution concentrations, the presence of a certain density of worms is beneficial to the water exchange, thereby reducing the concentration of river pollutants.

However, the measurement of VWF in this study uses conservative solutes, which may be more suitable to reflect the exchange of non-reactive pollutants at the sediment-water interface, and is by no means a broad representative. The exchange and transformation of reactive solutes is definitely more complicated, involving biochemical reactions, and further experimental studies are needed. Moreover, each species has its own function, which can be studied more diversely in the future.

\section{Conclusions}

Our research shows that tubificid worms cause effects on the vertical water flux and penetration depth across the SWI and such effects have markable correlation with both density and duration of bioturbation. Within a certain period, when the tubificid density was less than or equal to 20 individual/10 $\mathrm{cm}^{2}$, bioturbation promoted the VWF at the SWI, however, once it exceeded or equaled to 25 individual/10 $\mathrm{cm}^{2}$, negative correlation presented between bioturbation and VWF. However, after reaching a certain time, between day 14 and day 21, the positive impact weakened or even became negative under all density conditions. Moreover, bioturbation of tubificid worms can increase the maximum penetration depth with increasing density. The above effects indicated a correlation between the tubificid density and the water exchange of the SWI. However, this experiment only obtained a short-term result. Additionally, combination of multi-species was not set in this experiment. Future studies should focus on multiple species with a longer experiment period, which would shed light on the more realistic bioturbation on a community level. The results are beneficial to understanding the importance of macroinvertebrate density in river ecosystems, while having certain reference significance to explaining the spatiotemporal heterogeneity of local water exchange.

Author Contributions: R.M. carried out experiments and wrote the paper. J.S. contributed in conceiving and designing the research. D.C. provided some guiding suggestions. J.W., X.Q., C.M., and M.L. assisted in the experiment. H.S. helped revise the manuscript. All authors have read and agreed to the published version of the manuscript.

Funding: This work was supported by the National Natural Science Foundation of China (Grant No. 51679200), Science and Technology Project of Shaanxi Provincial Water Resources Department (Grant No. 2018slkj-12) and Hundred Talents Project of the Chinese Academy of Sciences (Grant No. A315021406).

Acknowledgments: We are grateful to members for the experiment assistance. In particular, we are grateful to the editor and anonymous reviewers for providing valuable comments and suggestions, which helped improve the manuscript.

Conflicts of Interest: The authors declare no conflict of interest.

\section{References}

1. Krause, S.; Hannah, D.M.; Fleckenstein, J.H. Hyporheic hydrology: Interactions at the groundwater-surface water interface. Hydrol. Process. 2009, 23, 2103-2107. [CrossRef]

2. Findlay, S. Importance of surface-subsurface exchange in stream ecosystems: The hyporheic zone. Limnol. Oceanogr. 1995, 40, 159-164. [CrossRef]

3. Li, Y.; Hua, X.; Zheng, F.; Dong, D.; Liang, D.; Guo, Z. Effects of tubificid bioturbation on pore structures in sediment and the migration of sediment particles. Environ. Sci. Pollut. Res. 2016, 23, 8064-8075. [CrossRef] 
4. Chen, X.; Song, J.; Cheng, C.; Wang, D.; Lackey, S.O. A new method for mapping variability in vertical seepage flux in streambeds. Hydrogeol. J. 2008, 17, 519-525. [CrossRef]

5. Gualtieri, C. Interaction between hydrodynamics and mass-transfer at the sediment-water interface. In Proceedings of the Second Biennial Meeting: International Congress on Environmental Modelling and Software (iEMSs 2004), Osnabrück, Germany, 2 June 2004.

6. Boulton, A.J.; Datry, T.; Kasahara, T.; Mutz, M.; Stanford, J.A. Ecology and management of the hyporheic zone: Stream-groundwater interactions of running waters and their floodplains. J. N. Am. Benthol. Soc. 2010, 29, 26-40. [CrossRef]

7. Gualtieri, C. Bedform-induced hyporheic exchange: Impact of porous medium permeability. In Proceedings of the 7th International Congress on Environmental Modelling and Software (iEMSs 2014), San Diego, CA, USA, 15-19 June 2014.

8. Gualtieri, C. Effect of permeability on hyporheic flows across a triangular dune. In Essays on Fundamental and Applied Environmental Topics; Nova Science: New York, NY, USA, 2012; pp. 115-132.

9. Boano, F.; Poggi, D.; Revelli, R.; Ridolfi, L. Gravity-driven water exchange between streams and hyporheic zones. Geophys. Res. Lett. 2009, 36. [CrossRef]

10. Salehin, M.; Packman, A.I.; Paradis, M. Hyporheic exchange with heterogeneous streambeds: Laboratory experiments and modeling. Water Resour. Res. 2004, 40. [CrossRef]

11. Martone, I.; Gualtieri, C.; Endreny, T. Characterization of Hyporheic Exchange Drivers and Patterns within a Low-Gradient, First-Order, River Confluence during Low and High Flow. Water 2020, 12, 649. [CrossRef]

12. Mendoza-Lera, C.; Mutz, M. Microbial activity and sediment disturbance modulate the vertical water flux in sandy sediments. Freshw. Sci. 2013, 32, 26-38. [CrossRef]

13. Jones, C.G.; Lawton, J.H.; Shachak, M. Organisms as ecosystem engineers. In Ecosystem Management; Springer: New York, NY, USA, 1994; pp. 130-147.

14. Marmonier, P.; Archambaud, G.; Belaidi, N.; Bougon, N.; Breil, P.; Chauvet, E.; Claret, C.; Cornut, J.; Datry, T.; Dole-Olivier, M.-J.; et al. The role of organisms in hyporheic processes: Gaps in current knowledge, needs for future research and applications. Ann. Limnol. Int. J. Limnol. 2012, 48, 253-266. [CrossRef]

15. Nogaro, G.; Mermillod-Blondin, F.; Valett, M.H.; François-Carcaillet, F.; Gaudet, J.-P.; Lafont, M.; Gibert, J. Ecosystem engineering at the sediment-water interface: Bioturbation and consumer-substrate interaction. Oecologia 2009, 161, 125-138. [CrossRef] [PubMed]

16. Xu, M.-Z.; Wang, Z.; Pan, B.-Z.; Zhao, N. Distribution and species composition of macroinvertebrates in the hyporheic zone of bed sediment. Int. J. Sediment Res. 2012, 27, 129-140. [CrossRef]

17. Anschutz, P.; Ciutat, A.; Lecroart, P.; Gerino, M.; Boudou, A. Effects of Tubificid Worm Bioturbation on Freshwater Sediment Biogeochemistry. Aquat. Geochem. 2012, 18, 475-497. [CrossRef]

18. Kristensen, E.; Penha-Lopes, G.; Delefosse, M.; Valdemarsen, T.B.; Quintana, C.O.; Banta, G.T. What is bioturbation? The need for a precise definition for fauna in aquatic sciences. Mar. Ecol. Prog. Ser. 2012, 446, 285-302. [CrossRef]

19. Mermillod-Blondin, F. The functional significance of bioturbation and biodeposition on biogeochemical processes at the water-sediment interface in freshwater and marine ecosystems. J. N. Am. Benthol. Soc. 2011, 30, 770-778. [CrossRef]

20. Ojha, R.B.; Devkota, D. Earthworms: 'Soil and Ecosystem Engineers'-A Review. World J. Agric. Res. 2014, 2, 257-260. [CrossRef]

21. Mermillod-Blondin, F.; Rosenberg, R.; François-Carcaillet, F.; Norling, K.; Mauclaire, L. Influence of bioturbation by three benthic infaunal species on microbial communities and biogeochemical processes in marine sediment. Aquat. Microb. Ecol. 2004, 36, 271-284. [CrossRef]

22. Mermillod-Blondin, F.; Gaudet, J.-P.; Gerino, M.; Desrosiers, G.; Châtelliers, M.C.D. Influence of macroinvertebrates on physico-chemical and microbial processes in hyporheic sediments. Hydrol. Process. 2002, 17, 779-794. [CrossRef]

23. Mermillod-Blondin, F.; Gerino, M.; Degrange, V.; Lensi, R.; Chassé, J.-L.; Rard, M.; Châtelliers, M.C.D. Testing the functional redundancy of Limnodrilus and Tubifex (Oligochaeta, Tubificidae) in hyporheic sediments: An experimental study in microcosms. Can. J. Fish. Aquat. Sci. 2001, 58, 1747-1759. [CrossRef]

24. Mermillod-Blondin, F.; Gaudet, J.-P.; Gerino, M.; Desrosiers, G.; Jose, J.; Châtelliers, M.C.D. Relative influence of bioturbation and predation on organic matter processing in river sediments: A microcosm experiment. Freshw. Biol. 2004, 49, 895-912. [CrossRef] 
25. Lin, Q.; Song, J.; Gualtieri, C.; Cheng, D.; Su, P.; Wang, X.; Fu, J.; Peng, J. Effect of Hyporheic Exchange on Macroinvertebrate Community in the Weihe River Basin, China. Water 2020, 12, 457. [CrossRef]

26. Granéli, W. The influence of chironomus plumosus larvae on the exchange of dissolved substances between sediment and water. Hydrobiologia 1979, 66, 149-159. [CrossRef]

27. Boulton, A.J.; Findlay, S.; Marmonier, P.; Stanley, E.H.; Valett, H.M. The functional significance of the hyporheic zone in streams and rivers. Annu. Rev. Ecol. Syst. 1998, 29, 59-81. [CrossRef]

28. Chen, M.; Ding, S.; Liu, L.; Wang, Y.; Xing, X.; Wang, D.; Gong, M.; Zhang, C. Fine-scale bioturbation effects of tubificid worm (Limnodrilus hoffmeisteri) on the lability of phosphorus in sediments. Environ. Pollut. 2016, 219, 604-611. [CrossRef] [PubMed]

29. Zhang, L.; Gu, X.; Fan, C.; Shang, J.; Shen, Q.; Wang, Z.; Shen, J. Impact of different benthic animals on phosphorus dynamics across the sediment-water interface. J. Environ. Sci. 2010, 22, 1674-1682. [CrossRef]

30. Lagauzère, S.; Motelica-Heino, M.; Viollier, E.; Stora, G.; Bonzom, J.M. Remobilisation of uranium from contaminated freshwater sediments by bioturbation. Biogeosciences 2014, 11, 3381-3396. [CrossRef]

31. Di, S.; Cheng, C.; Chen, L.; Zhou, Z.; Diao, J. Effects of benthic organism Tubifex tubifex on hexachlorocyclohexane isomers transfer and distribution into freshwater sediment. Ecotoxicol. Environ. Saf. 2016, 126, 163-169. [CrossRef]

32. Lagauzère, S.; Terrail, R.; Bonzom, J.-M. Ecotoxicity of uranium to Tubifex tubifex worms (Annelida, Clitellata, Tubificidae) exposed to contaminated sediment. Ecotoxicol. Environ. Saf. 2009, 72, 527-537. [CrossRef]

33. Nikora, V.I.; Goring, D.G.; Biggs, B.J.F. Silverstream eco-hydraulics flume: Hydraulic design and tests. N. Z. J. Mar. Freshw. Res. 1998, 32, 607-620. [CrossRef]

34. Cheng, D.; Song, J.; Zhao, X.; Wang, S.; Lin, Q.; Peng, J.; Su, P.; Deng, W. Effects of chironomid larvae and Limnodrilus hoffmeisteri bioturbation on the distribution and flux of chromium at the sediment-water interface. J. Environ. Manag. 2019, 245, 151-159. [CrossRef]

35. Packman, A.I.; Salehin, M.; Zaramella, M. Hyporheic Exchange with Gravel Beds: Basic Hydrodynamic Interactions and Bedform-Induced Advective Flows. J. Hydraul. Eng. 2004, 130, 647-656. [CrossRef]

36. Song, J.; Ren, C.; Li, M.; Xue, J.; Yang, X. Study on the influence of tremor earthworm biological disturbance on sediment permeability in river underflow zone. J. Environ. Sci. 2014, 34, 2062-2069. (In Chinese) [CrossRef]

37. Mutz, M.; Kalbus, E.; Meinecke, S. Effect of instream wood on vertical water flux in low-energy sand bed flume experiments. Water Resour. Res. 2007, 43. [CrossRef]

38. Zhou, T.; Endreny, T.A. Reshaping of the hyporheic zone beneath river restoration structures: Flume and hydrodynamic experiments. Water Resour. Res. 2013, 49, 5009-5020. [CrossRef]

39. Dafoe, L.T.; Rygh, A.L.; Yang, B.; Gingras, M.K.; Pemberton, S.G. A New Technique for Assessing Tubificid Burrowing Activities, and Recognition of Biogenic Grading Formed by these oligochaetes. Palaios 2011, 26, 66-80. [CrossRef]

40. Lagauzère, S.; Boyer, P.; Stora, G.; Bonzom, J.-M. Effects of uranium-contaminated sediments on the bioturbation activity of Chironomus riparius larvae (Insecta, Diptera) and Tubifex tubifex worms (Annelida, Tubificidae). Chemosphere 2009, 76, 324-334. [CrossRef]

41. Fukuhara, H. The effect of tubificids and chironomids on particle redistribution of lake sediment. Ecol. Res. 1987, 2, 255-264. [CrossRef]

42. Elliott, A.H.; Brooks, N.H. Transfer of nonsorbing solutes to a streambed with bed forms: Laboratory experiments. Water Resour. Res. 1997, 33, 137-151. [CrossRef]

43. Elliott, A.H.; Brooks, N.H. Transfer of nonsorbing solutes to a streambed with bed forms: Theory. Water Resour. Res. 1997, 33, 123-136. [CrossRef]

44. Nie, X.; Huang, T.; Zhang, J.; Li, W.; Li, X.; Wang, B. Effects of sediment properties and distribution density on the movement of vermiformes. J. Environ. Sci. 2010, 1, 105-112. (In Chinese) [CrossRef]

45. He, Y.; Men, B.; Yang, X.; Wang, D. Bioturbation/bioirrigation effect on thallium released from reservoir sediment by different organism types. Sci. Total Environ. 2015, 532, 617-624. [CrossRef] [PubMed]

Publisher's Note: MDPI stays neutral with regard to jurisdictional claims in published maps and institutional affiliations. 